\title{
The Dynamics of Internet Access Among Autistic Children's Parents
}

\author{
Ragil Tri Atmi ${ }^{1 \mathrm{a}} ;$ Fitri Mutia $^{1}$ \\ ${ }^{1}$ Department Library of Information Science, Airlangga University, Surabaya, Indonesia \\ ${ }^{a}$ Corresponding author: ragil.tri.atmi@fisip.unair.ac.id
}

\begin{abstract}
Parents are the main factors to support the growth of childrens autism, but many parents still are embarrassed and shut herself away from her social environment. The Internet helps to do self actualisation and developing group owned by her children. The Internet is also helping them to access about the growth needs of autistic children, the problem is parents have different of behavior and the ability to access the internet. The purpose of this study was to describe the behavior of internet access on parents who have autistic children. The researchers used a qualitative method, The number of informants was five person, while in getting the informants using techniques snowball. The concept used is Information behavior and internet literacy. The results of this research show that the behavior of internet information access parents effected by the characteristics of autistic children. Characteristics of autistic children are distinguished into two, the behavior of autistic children are active and passive. Autistic children actively motivate parents have internet literacy, while autistic children passive aspects influenced his parents don't have internet literacy. The conclusion that internet literacy necessary for parents of children with autism, active and passive, especially to help meet the information needs of the growth of her children, as well as fostering confidence and potential of his son.
\end{abstract}

Keywords-internet access behavior, information behavior, internet literacy, autistic children's parents

\section{INTRODUCTION}

The Internet helps meet the needs of parents of children with Autism attention deficit hyperactive disorder (ADHD). Those needs include the health, growth, education to the needs of actualizing and socializing, but not all parents have the ability to access the internet. The ability to use technology is a basic capability that must be owned by any user to access the internet. The ability to use the internet both useful to support learning, productivity, making decision, and tasks [1]. Ideally the parents of autistic children have internet literacy, as capital activities in accessing information on the internet. Access information on the internet is part of the behavioral information. This behavior is caused due to a necessity, whereas the needs of autistic children and characteristic are different, so too with the ability to access the parents. That means the behavior of the access the internet are very complex, not only as an internet literacy however there are many aspects of both internal and external that support or inhibit behavior. This study wanted to find out how the internet access among autistic childrens parents. in Indonesia the study of internet access on autistic children's parents still rare. The main objective of this study was to contribute to theoretical or applicative thinking for the development of scientific observers, autistic children and parents of children with autism.

\section{RESEARCH METHOD}

This study uses descriptive qualitative approach and five informant. using snowball sampling. Primary data retrieval by doing in-depth interviews, while the secondary data from literature books and journals. Researchers analyze the data by using the concept of internet literacy and behavioural information. Internet literacy is the ability of how to operate the device technology to be used as a medium in accessing, know, understand, analyze, share, and producing information through the medium of the internet. Internet literacy is divided into two internet literacy skills i.e. the ability of a use of the internet and internet information literacy, i.e. the ability to understand, filter, analyze, criticize and produce information on the internet [2]. Internet literacy is also a series of actions that begins from searching for information needs, the use of effective strategies in search, analyze the results, criticize and evaluate information, view source, and how the success of the information search brings the influence on him [3] The other opinions also explained that the internet literacy is interact of activities with technology and online media includes culture communicate and his habit [4]. The behavioral information is human related to resources and information, including a search behavior and usage information is either actively or passively [5] Interruption behavior of autistic children divided into three behaviors, social interaction and communication and language [6]. 


\section{RESULT AND DISCUSSION}

\section{A. The behavior of internet access.}

Basically internet access behavior is part of the behavioral information. The interpretation that behavior and access the internet are actions or activities of humans interacting with the internet, including links to the tools already connect to the internet. Activity and access aims to create, find, find, get and use information with certain acupuncture strategy through the medium of the internet.

\section{B. The internet Literacy}

The internet Literacy is divided into the first two is any ability to use, understand, apply all the facilities available on the internet, while the second is the ability to understand, filter, evaluate, use and produce and being critically at the information available on the internet.

\section{Impaired autistic children's behavior.}

The researchers classify two types of autistic children are passive and active. Passive autism has limitations for communication and language and social interactions, while the active behavior has no disruption in social interaction and communication and language.

\section{The behavior of internet access between parents of children with autism}

\section{The first Informant.}

The first informant is the mother who has two boys who have Autism attention deficit hyperactivity disorder (ADHD). Saying that access the internet when having a blackberry cell phone. She is rarely and access information for her superbly through the internet, the need for a second information obtained by her son through the sharing between parents of other autistic children. She is also has no social media to share information, but media experts in using the tools as well as social media, She has limits the kids play the internet, allowing her son to play when things are guarding it. A wide range of features and fasilities that are available in the internet really mastered well, but none are actively exploited. The flurry of make it do not have the time to interact Conference with online media. "I rarely use the internet to meet the information needs of both my children, but will scrutinise the information if the information is wrong, let alone dealing with the condition and the growth of an autistic child, I only consume" her two sons including on autistic passive.

\section{The second Informant.}

The second informant, was as mother with children a single male who have Autism attention deficit hyperactivity disorder (ADHD). Her son belongs to has a very high IQ and musical talent and communicate that very well. The condition of her son make the active parent access information on the internet. She is always actively campaigned about the growth of autistic children through social media either comment or status in the column he also actively searching the information through a variety of sources on the internet, which sought the head superbly, child development talent and a group of autistic children, as well as civic information for his son. "I know if my child is smart and talented, so I motivated to upload its activities in social media, my children also have social media, I am also actively looking for information on a wide variety of news sources both in and outside the country for the education of my child, I tell him that the limitations in and accessing information on the internet "She claimed to be using a lot of gadgets to and accesses, The active condition make her always want to add to the knowledge and ability using the internet." I often write a comment to motivate other moms in my social media, I am also critical when a news story I read about an autistic child is right"

\section{The third informant}

The third informant, was a mother who had a boy that Autism attention deficit hyperactivity disorder (ADHD). Her son belongs to have a very high IQ, had a talent that very much especially the originality in the field of the visual drawing, have the ability to communicate and socialize. The mother is proud, so that makes her always and accessing information over the internet. A variety of information on health, as well as the talent of thousands of searchable via search engines. Using a tablet and a computer in access. She often writes the activity and growth of children in some of the social media. "I national interact with the internet because of the child. I am more motivated to get information and share it with other parents through social media, I am also a frequent presenter to motivate other parents both online and offline, I am proud of my child"

\section{The fourth Informant}

The fourth informant is a music entrepreneur who has a daughter who has Autism attention deficit hyperactive disorder (ADHD). Her son belongs in children who have a disadvantage in communicating and socializing, reticent. This condition makes it very passive, using the internet is only used for socialize with peer group. He also read a few articles on google about the growth of an autistic child, but is not alone, but rather ask for help from family members. "I know if information is widely available on the internet, but didn't know how, I often ask my child please others to access the information, if that is not true about autistic children, I am silent, I do no to know how to commenting, my children could bathe and eat alone, is enough for me, no matter with others" 


\section{The fifth informant}

The informant was the fifth mother of a boy with Autism attention deficit hyperactive disorder (ADHD). Her son is reticent and the ability to communicate and socialize not well. Seeing her son's condition, her mother resigned in her social environment, and she does not motivate and obtain information on the internet. The limit of themselves interact to internet. "I know my son's condition, I think it is important that the child can be independent, eating and bathing themselves, $i$ think is enough, a lot of information available on the internet, but I was mediocre, my child's condition is indeed like this, I resigned, any information $i$ will thank without my commentary".

Based on the findings of the data, the researchers provide internet access to the two categories of behavior typologi. The first is active parents who have internet literacy and passive parent who does not have internet literacy. Active parents have an active behavior of interacting with the internet, while the passive parent who is not doing his interaction with the internet. Factors that affect aspects of the parents have an active and passive action is a characteristic property of the child. The characteristics of passive children is the parent factor does not access the internet. They consider that the conditions of his son is the destiny of a God who cannot be cured. This condition makes the parents who don't do access, the effect of those who do not have internet literate, tend to be indifferent to all the information received, on active parenting typologi will do the access on the internet. This aspect is affected they have good internet literacy. They consider that the actions and help them get access to information about her son who has been its effect on the actualization of children. Kids are more productive, such as height, pictures and music. More active children are increasingly making parents proud, so proud taste makes them addictive and access the internet. As for the behavior of the access to information whether it is to find, create and use information on search engines and social media, such as Pendit said [5] The behavior of information related to human resources and information behaviour, or acting on, information sources used in elderly people is a source of information on the internet, they are motivated to interact again with a source of information because it is driven by a factor of success. Those who feel the actions access benefits for child growth, While actualizing it motivates them to constantly generate information through social media, like making writing about the successful application of diet for autistic children as Henry, [3] that the internet is literacy action begins from searching for information needs, the later success of search information needs bring influence on him, while EM and Kim Soeun [2] said that one of the internet literacy components of producing information that is available on the internet. The interpretation that when the Act of generating the information passed and carried out by parents who act they categories in place of metal casting that has internet literacy. Other opinions also reaffirmed by shields and Behrman [4] that internet literacy not only interact with the internet, but the associated habit then happens to discuss culture. The interpretation that the behavior and constant access to custom parents of children with autism.

\section{CONCLUSION}

The behavior of the access the internet by parents of children with Autism to attention deficit hyperactivity disorder (ADHD) effected by the factors of the condition of children. A child who has a passive condition does not motivate parents to access information on the internet, passive conditions are major factors they don't have a good internet literacy. While the characteristics of active parents motivate children access information on the internet. Active children are parents have good internet literacy. Ideally the parent who has a child is passive as well as active can make use of the internet as a medium to help them meet the needs of information, updates, communication and social needs of children Autism attention deficit hyperactivity disorder (ADHD).

\section{REFERENCES}

[1] N. Kalantzis, Cope, B., \& Cloonan, A. "A multiliteracies perspective on new literacies. In E.A Baker (Ed), The new literacies: Multiple perpective on research and practice, New York, NY: The Guilford Press, 2010, pp. 61-87.

[2] E.M. Kim, Y. Soeun. Internet literacy and digital natives civic engagement: Internet skill literacy or Internet information literacy, United Kindom:Journal of Youth Studies,;2016, 1(9:4), p 438-456. Available online: http://dx.doi.org/10.1080/13676261.2015.1083961.

[3] L.A. Henry, "Searching for an answer: The citical role of new literacies while reading on the internet. The Reading Teacher, 2006, 59 (7), 614627.Available online http://www.reading.org/General/Publications/Journals/RT.aspx.

[4] M. Shields, R.E. Behrman, "Children and computer technology: Analysis and recommendations. The Future of Children, 2000, 10(2), 443. Available online: http://www.futureofchildren.org/

[5] P.L. Pendit, "Penelitian Ilmu Perpustakaan: Suatu Pengantar Diskusi Epistemologi dan Metodologi, Jakarta: Jip-Fsui. 2003.

[6] J. Yuwono, Memahami Anak Atistik:Kajian Teoritik dan Empirik, Bandung:Afabeta. 2009. 